
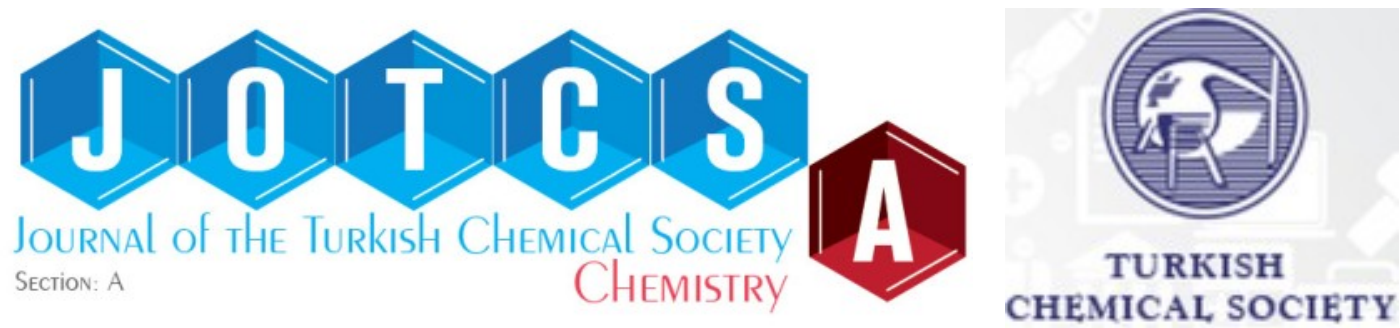

\title{
Quercetin particles with lower inhibitory activity for $\alpha$-glucosidase and negligible effects on blood clotting
}

\author{
Mehtap SAHINER ${ }^{1 *} \square$ and Selin Sagbas SUNER ${ }^{2}$ \\ ${ }^{1}$ Department of Fashion Design, Canakkale Applied Science, Canakkale Onsekiz Mart University, Terzioglu \\ Campus, 17100, Canakkale, Turkey. \\ 2Department of Chemistry, Faculty of Science and Arts, Canakkale Onsekiz Mart University, Terzioglu \\ Campus, 17100, Canakkale, Turkey
}

\begin{abstract}
Poly(quercetin) (p(QR)) particles were synthesized by using poly (ethylene glycol) diglycidyl ether (PEGGE) crosslinker in a single step via a microemulsion system. The morphological, size, and functional analysis of the prepared particles were examined by optical microscope, scanning electron microscope (SEM), dynamic light scattering (DLS) measurements, and FT-IR spectroscopy. P(QR) particles were found to have spherical shape with $372 \pm 9 \mathrm{~nm}$ size range based on SEM images and DLS measurements. The zeta potential measurements, performed at different $\mathrm{pH}$ conditions, and potentiometric titration of $\mathrm{p}(\mathrm{QR})$ particles revealed that the isoelectric point and $\mathrm{pKa}$ values were around $\mathrm{pH} 2.5$ and 2.3 , respectively. Ferric reducing antioxidant power (FRAP) was determined for $\mathrm{QR}$ and $\mathrm{p}(\mathrm{QR})$ particles at $\mathrm{pH} 3.6$ and found to be 9.4 and $0.43 \mu \mathrm{g}$ of reduced $\mathrm{Fe}(\mathrm{II})$. The effects of $\mathrm{QR}$ and $\mathrm{p}(\mathrm{QR})$ particles on $\alpha$-glucosidase enzyme activity were investigated at $\mathrm{pH} 6.9$ and QR molecules and $\mathrm{p}(\mathrm{QR})$ particles can inhibit the $\alpha$-glucosidase enzyme by $89.3 \%$ and $24.7 \%$, respectively. The fluorescence spectroscopy of $Q R$ and $p(Q R)$ with fibrinogen showed that $p(Q R)$ particles do not induce clotting of blood.
\end{abstract}

Keywords: Quercetin particles; $\alpha$-glucosidase inhibitor; fibrinogen binding; antioxidant.

Submitted: November 14, 2020. Accepted: February 22, 2021.

Cite this: Sahiner M, Suner SS. Quercetin particles with lower inhibitory activity for $\alpha$-glucosidase and negligible effects on blood clotting. JOTCSA. 2021;8(2):443-52.

DOI: https://doi.org/10.18596/jotcsa.825868.

*Corresponding author. E-mail: sahinerm78@gmail.com.

\section{INTRODUCTION}

Polyphenolics obtained from natural sources are known as flavonoids and have natural antioxidant and antibacterial properties due to the hydroxyl groups in their chemical structure. They are usually found in fruits, roots, leaves or stems of plants (1-3). As they possess antioxidant, antimicrobial and hemostatic properties, polyphenolics are potentially considered as drugs for healing cancers and wounds and attract great interest in many areas including medicine, food, and cosmetics (4-7). Quercetin (QR) is a flavonoid commonly found in many plants such as onion, tea, apple peel, parsley, citrus, sage, white grapes, red grapes and so on. It was shown in vivo and in vitro that quercetin can prevent oxidative stress by capturing free radicals in the body due to antioxidant properties, can be used in the treatment of hypertension by lowering blood pressure, and can prevent inflammation with anti-cancer effects (3).
Some flavonoids such as quercetin are used in the body and they can interact with enzymes causing their activation and/or inactivation (inhibition) (8).

It is recognized that enzymes break down sugar and when long chain sugars are broken down into a single molecule sugar unit in the body, they can pass into the blood causing an increase in glucose level of the blood. There are many treatments for high glucose levels, e.g., the use of insulin hormone for the treatment of hyperglycemia. Also, one of these treatments is inhibition of the $\alpha$-glucosidase enzyme, and some flavonoids are known to inhibit the $\alpha$-amylase enzyme (8-10).

In the biomedical applications of any materials, there are always interactions with blood and cells that need to be considered seriously. Fibrinogen is one of the human plasma proteins that has significant and effective role in the coagulation of blood 
and cell adhesion. The concentration of fibrinogen in the human body can change in the $2-4 \mathrm{~g} / \mathrm{L}$ range (11). During the blood coagulation process, fibrinogen interacts with thrombin resulting in conversion to fibrin and subsequent clot formation. Preserving the proper protein structure and conformation are also significant factors to maintain the activity of fibrinogen. Alteration of fibrinogen is therefore an essential method to study the interaction between materials and blood (12).

Earlier, our group reported the preparation of $p(Q R)$ nanoparticles by cross-linking QR molecules with polyethylene glycol glycidyl ether (PEGGE) in lecithin-gasoline reverse micellar microemulsion (13). The hydrolytic degradation, hemolysis, blood clotting index for human blood, cytotoxicity, and cancer cell viability were reported (13). Here, we report the effects of $Q R$ and $p(Q R)$ on $\alpha$-glucosidase enzyme activity. The solutions of QR molecule and $\mathrm{p}(\mathrm{QR})$ particles at different concentrations were incubated with $\alpha$-glucosidase enzyme at $\mathrm{pH} 6.9$ to determine the inhibition capability. Furthermore, the interaction of $Q R$ and $p(Q R)$ with fibrinogen was investigated to estimate the coagulation effects in blood.

\section{MATERIAL AND METHOD}

\section{Materials}

Quercetin dehydrate (QR, Sigma, >95\%), L- $\alpha$ lecithin (granular, Acros Organic, 98\%), poly (ethylene glycol) diglycidyl ether (PEGGE, Mn: 500, Aldrich), triethylamine (TEA, 99.5\%, Sigma Aldrich) sodium hydroxide (Sigma-Aldrich), gasoline (95 octane, Total), cyclohexane (99.5\%, Sigma-Aldrich), and ethyl alcohol (Birkim, 9\%) were used as received. Ultra-pure distilled water was obtained from GFL, 2108 and Millipore Direct-Q3 UV (18,2 MS.cm). Sodium nitrite from Acros, aluminum chloride (Alfa Aesar), 5,6-Diphenyl-3-(2-pyridyl)-1,2,4-triazine-4,4disulfonic acid disodium salt hydrate (Alfa Aesar), sodium acetate anhydrous (Fisher, 99\%), and hydrochloric acid (Sigma, 37\%) were used for antioxidant tests. Bovine fibrinogen (Alfa Aesar) was used for fibrinogen interaction. $\alpha$-Glucosidase from Saccharomyces cerevisiae (Sigma Aldrich) and p-nitrophenyl- $\alpha$-D-glucopyranose (Sigma Aldrich) were used for $\alpha$-glucosidase activity.

\section{Synthesis of $p(Q R)$ particles}

$\mathrm{P}(\mathrm{QR})$ particles were synthesized by using PEGGE as crosslinker in lecithin-gasoline microemulsion medium according to a previous procedure with some modifications $(13,14)$. In short, $3 \mathrm{~mL}$ of $0.1 \mathrm{~g} /$ $\mathrm{mL}$ concentration of $\mathrm{QR}$ in $1 \mathrm{M} \mathrm{NaOH}$ aqueous solution was placed in $150 \mathrm{~mL} 0.1$ M lecithingasoline solution at $50{ }^{\circ} \mathrm{C}$ at $750 \mathrm{rpm}$ mixing rate. After $10 \mathrm{~min}$, PEGGE at $300 \%$ mole ratio of QR and $20 \mu \mathrm{L}$ triethylamine as accelerator were added into the emulsion medium under constant mixing and the reaction continued for $12 \mathrm{~h}$ at $50{ }^{\circ} \mathrm{C}$. The prepared $\mathrm{p}(\mathrm{QR})$ particles were precipitated via centrifuge at $10,000 \mathrm{rpm}$ for $10 \mathrm{~min}$. Then, the precipitated $\mathrm{p}(\mathrm{QR})$ particles were washed with gasoline and cyclohexane, ethanol:water mixture three times and then with acetone by using centrifugation to precipitate/resuspend at 10,000 rpm for $10 \mathrm{~min}$. The prepared $\mathrm{p}(\mathrm{QR})$ particles were dried in an oven at $50{ }^{\circ} \mathrm{C}$ for further use.

\section{Characterization of $\mathbf{p}(\mathbf{Q R})$ particles}

The morphological structure of $p(Q R)$ particles was assessed by optical microscope (Olympus BX-53) and scanning electron microscope (SEM, Jeol JSM5600 LV). For SEM analysis, $\mathrm{p}(\mathrm{QR})$ particles were coated with gold/palladium and analyzed at $20 \mathrm{kV}$ operating voltage. Hydrodynamic size distribution of $\mathrm{p}(\mathrm{QR})$ particles was determined by dynamic light scattering (DLS, Brookhaven Ins. Corp., 90Plus/BIMAS). Zeta potential (ZP) measurements of the particles were completed by using Brookhaven Inst. Corp., BIC ZetaPlus analyzer at different solution pHs. Briefly, $10 \mathrm{mg}$ of $\mathrm{p}(\mathrm{QR})$ particles were dispersed in $0.001 \mathrm{M} 50 \mathrm{~mL} \mathrm{KCl}$ aqueous solution and the $\mathrm{ZP}$ of the particles was measured in the $\mathrm{pH}$ 2-12 range to calculate the isoelectric point (IEP) of $\mathrm{p}(\mathrm{QR})$ particles. DLS and ZP analyses were measured ten times and the obtained results are given as averages with corresponding standard deviations. Potentiometric titration of $p(Q R)$ particles was carried to determine the equivalent point and $\mathrm{pKa}$ values of $\mathrm{p}(\mathrm{QR})$ particles. Briefly, $50 \mathrm{mg} \mathrm{p}(\mathrm{QR})$ particles were suspended in $0.01 \mathrm{M} 50 \mathrm{~mL} \mathrm{KCl}$ aqueous solution, and the $\mathrm{pH}$ of this suspension was adjusted to 2 by using $0.01 \mathrm{M} \mathrm{HCl}$ aqueous solution and titrated by using $0.01 \mathrm{M} \mathrm{NaOH}$ aqueous solution up to $\mathrm{pH}$ 12. Thermogravimetric analysis (TGA) of $\mathrm{p}(\mathrm{QR})$ particles was done by using a TG analyzer (SII TG/DTA 6300, Japan) in the temperature range 50$1000{ }^{\circ} \mathrm{C} . \mathrm{P}(\mathrm{QR})$ particles weighing about $5 \mathrm{mg}$ were heated at $10{ }^{\circ} \mathrm{C} / \mathrm{mL}$ heating rate under $\mathrm{N}_{2}$ atmosphere with $100 \mathrm{~mL} / \mathrm{min}$ flow rate.

\section{Determination of antioxidant properties of p(QR) via iron reduction potential FRAP TEST}

The iron reduction potential (FRAP) of $Q R$ and $p(Q R)$ particles was investigated with a UV-Vis spectrophotometer at $595 \mathrm{~nm}$ according to the literature $(15,16)$. Briefly, $0.3 \mathrm{M}$ acetate buffer was prepared at $\mathrm{pH}$ 3.6. Tripyridyl triazine (TPTZ) solution at $10 \mathrm{mM}$ concentration was prepared using $2.5 \mathrm{~mL} 40 \mathrm{mM} \mathrm{HCl}$. Acetate buffer with $25 \mathrm{~mL}$ volume was mixed with $2.5 \mathrm{~mL}$ of TPTZ solution and $2.5 \mathrm{~mL}$ of $20 \mathrm{mM} \mathrm{FeCl}{ }_{3} \mathrm{H}_{2} \mathrm{O}$ (in acetate buffer) was mixed to obtain Fe(III)- TPTZ complex. P(QR) were suspended in acetate buffer at $0.5 \mathrm{mg} / \mathrm{mL}$ and $\mathrm{QR}$ molecules were dissolved in ethanol at $0.5 \mathrm{mg} / \mathrm{mL}$. The FRAP test was done using $3 \mathrm{~mL}$ of the prepared Fe-TPTZ complex solution.

$\mathrm{QR}$ solution and $\mathrm{p}(\mathrm{QR})$ suspended particles were prepared as $0.5 \mathrm{mg} / \mathrm{mL}$ solution. First, the UV-visible spectra of the Fe-TPTZ complex was measured at $595 \mathrm{~nm}$, and 5-80 $\mu \mathrm{L}$ volumes of $\mathrm{QR}$ and/or $\mathrm{p}(\mathrm{QR})$ particle suspensions were placed into Fe-TPTZ complex solution and stirred for 4 minutes with plastic pipette tips. Then, the UV-Vis spectra was 
recorded and the difference between the absorbance values was calculated as $\mu \mathrm{mol} \mathrm{Fe}(\mathrm{II})$ reduced. $\mathrm{FeSO}_{4} \cdot 7 \mathrm{H}_{2} \mathrm{O}$ was used as the $\mathrm{Fe}(\mathrm{II})$ source to complex with TPTZ as standard to generate a calibration curve to be used in determination of $\mathrm{Fe}(\mathrm{II})$ reduced by $\mathrm{QR}$ and/or $\mathrm{p}(\mathrm{QR})$ particles. Gallic acid (GA) was taken as a reference material.

\section{Total flavonoid content (TFC) of QR and $p(Q R)$ particles}

The TFC tests for $Q R$ and $p(Q R)$ were done using a UV-Vis spectrophotometer at $405 \mathrm{~nm}$ in accordance with the literature with some modifications (17). QR solution and $\mathrm{p}(\mathrm{QR})$ particle suspension in distilled water at $170 \mathrm{ppm}$ and $0.5 \mathrm{~mL}$ volume was placed in 10-mL tubes. Distilled water, $2 \mathrm{~mL}$, was added to these $10-\mathrm{mL}$ tubes. 5 minutes later, $0.15 \mathrm{~mL}$ of $5 \%$ $\mathrm{NaNO}_{2}$ was added and after another 5 minutes, 0.15 $\mathrm{mL}$ of $10 \% \mathrm{AlCl}_{3} \cdot 6 \mathrm{H}_{2} \mathrm{O}$ was added to this medium. After another 5 minutes, $1 \mathrm{M} 1 \mathrm{~mL}$ of $\mathrm{NaOH}$ was added to this mixture. After keeping this solution still for another 15 minutes, the UV-Vis spectrum of this solution was read at $405 \mathrm{~nm}$. $\mathrm{NaNO}_{2}$ and $\mathrm{AlCl}_{3} \cdot 6 \mathrm{H}_{2} \mathrm{O}$ mixture solution in DI water was used as blank. Gallic acid was used as standard.

\section{Inhibitory capacity of $Q R$ and $p(Q R)$ for $\alpha$ - glucosidase}

The inhibition capacity of $Q R$ and $p(Q R)$ particles for the enzyme, $\alpha$-glucosidase, was examined according to the reported literature (18-20). The QR solution was prepared at $0.075,0.15,0.3$ and $0.375 \mathrm{mg} / \mathrm{mL}$ concentrations. From these solutions, $70 \mu \mathrm{L}$ was taken, placed in 96 well-plates and incubated for 10 minutes. To these solutions, $70 \mu \mathrm{L}$ of enzyme solution at $0.06 \mathrm{unit} / \mathrm{mL}$ was added. Then, $70 \mu \mathrm{L}$ substrate (1.66 mM p-nitrophenyl- $\alpha$-D-glucoside solution in $67 \mathrm{mM}$ phosphate buffer) was added and left for 30 minutes and the absorbance value was measured at $405 \mathrm{~nm}$ using a micro plate reader (Thermo Multiskan Go). Inhibition\% values were calculated using equation (1) and compared to a control with $70 \mu \mathrm{L}$ buffer solution in place of the $\mathrm{QR}$ or $\mathrm{p}(\mathrm{QR})$ eluate $(18,20)$. For $\mathrm{p}(\mathrm{QR})$ particles, 0.375 , $0.75,1.5$ and $3 \mathrm{mg} / \mathrm{mL}$ suspensions were prepared and added to the well-plates and the same procedures were carried out.
Inhibition of $\alpha-$ glucosidase enzyme $\%=\left(\left[1-\frac{\Delta A_{405}^{\text {Sample }}}{\Delta A_{405}^{\text {Control }}}\right]\right) \times 100$
Inhibition of $\alpha-$ glucosidase enzyme $\%=\left(\left[1-\frac{\Delta A_{405}^{\text {Sample }}}{\Delta A_{405}^{\text {Control }}}\right]\right) \times 100$

Equation (1)

\section{Fibrinogen interaction}

The interactions of $Q R$ and $p(Q R)$ particles with fibrinogen were investigated according to the literature (13). The effect of $Q R$ and $p(Q R)$ on the fluorescence properties of fibrinogen was monitored by fluorescence spectroscopy (Thermo Scientific Lumina Spectrophotometer). A fibrinogen solution at $0.2 \mathrm{mg} / \mathrm{mL}$ concentration was prepared in distilled water. Different concentrations of $Q R$ or $p(Q R), 15-$ $250 \mu \mathrm{g} / \mathrm{mL}$ in PBS, were mixed with fibrinogen solution in 1:1 ratio by volume. The width of the excitation and emission slit was set as $5 \mathrm{~nm}$ and the excitation wavelength of $280 \mathrm{~nm}$ was used. The scanning range was set between 280-420 $\mathrm{nm}$. The interaction of $Q R$ and $p(Q R)$ particles with fibrinogen was determined in terms of the reduction in the fluorescence intensity.

\section{RESULTS AND DISCUSSION}

Quercetin (QR) is a well-known flavonoid-based phenolic that has promising use in a wide range of biological applications including as antimicrobial, antioxidant, anticancer, and anti-inflammatory material (21-24). The phenolic structure of QR was considered to be monomeric and was crosslinked with an epoxy group containing crosslinkers, e.g., PEGGE, to prepare degradable $p(Q R)$ particles. In $\mathrm{p}(\mathrm{QR})$ particle synthesis, $\mathrm{QR}$ was dissolved in basic aqueous solution and transferred to a lecithingasoline microemulsion solution to create water-inoil emulsion medium. PEGGE as crosslinker was added into the reaction medium containing epoxy groups can readily react with phenolic hydroxyl groups on quercetin in basic conditions. Sahiner et al. reported the synthesis, characterization, and degradability of $\mathrm{p}(\mathrm{QR})$ particles crosslinked with PEGGE (14). Also, the antioxidant, blood compatibility, cytotoxicity, and anticancer properties of these particles were reported (14). In this study, the degradable $\mathrm{p}(\mathrm{QR})$ particles were prepared with the same process to investigate their binding and/or inhibitory effect on alpha glycosidase enzyme activity for blood clotting mechanisms. The sizes of $\mathrm{p}(\mathrm{QR})$ particles were illustrated by optic microscope and SEM images as shown in Figure $1 \mathrm{a}$ and $1 \mathrm{~b}$. 

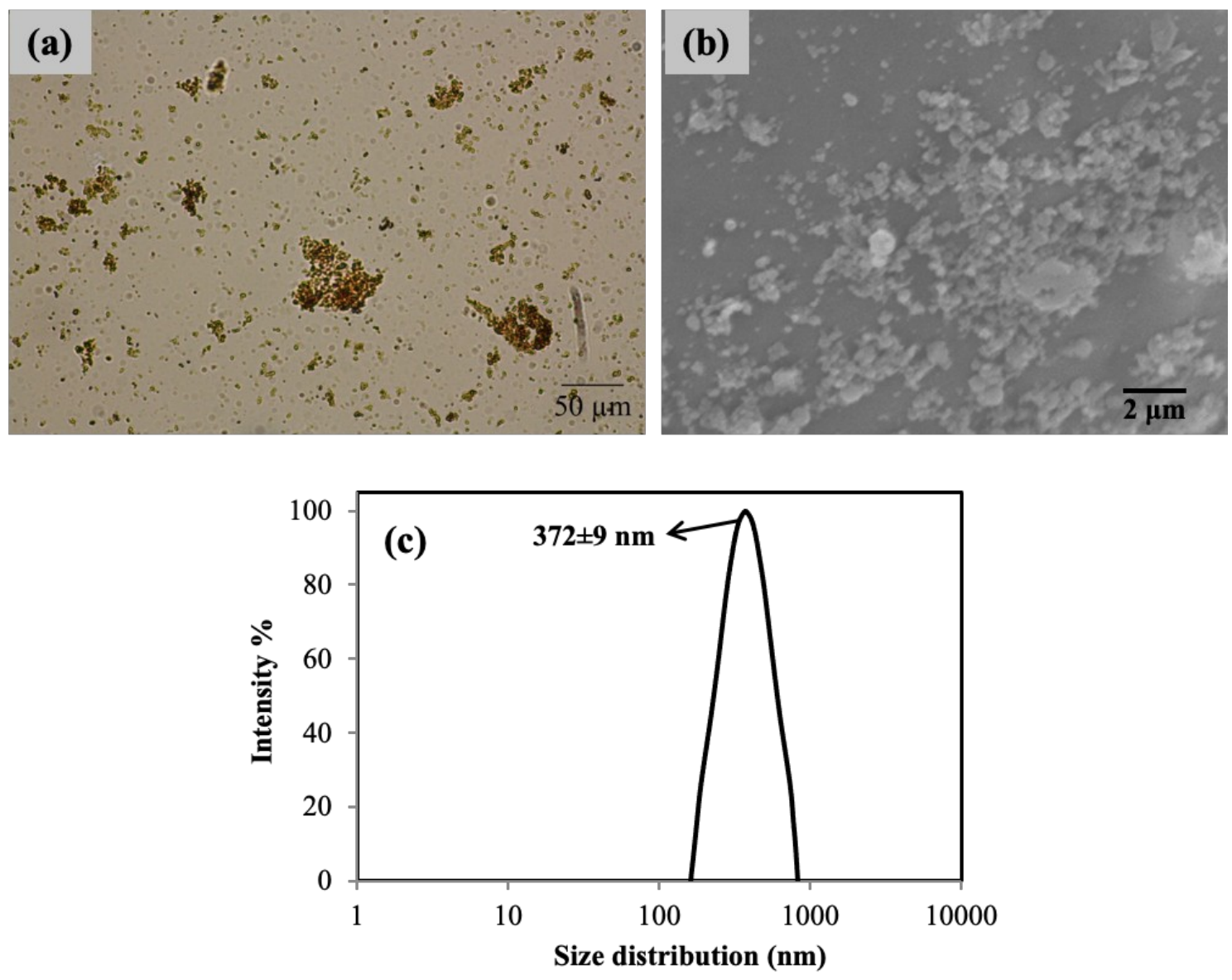

Figure 1. (a) Optical microscope and (b) SEM images of $p(Q R)$ particles and (c) hydrodynamic size distribution.

It is obvious from the images that $p(Q R)$ particles are spherical with sub-micron size range. The hydrodynamic size distribution of the $p(Q R)$ particles was measured between $160 \mathrm{~nm}$ and $820 \mathrm{~nm}$ size range with $372 \pm 9 \mathrm{~nm}$ average particle size. These results signified that the prepared $p(Q R)$ particles have nanometer size range and can be used as an injectable material for in vitro and in vivo applications.
Thermal degradation of PEGGE-crosslinked $p(Q R)$ particles was determined by thermogravimetric analysis (TGA) by heating about $5 \mathrm{mg} p(\mathrm{QR})$ particles from $50{ }^{\circ} \mathrm{C}$ to $1000{ }^{\circ} \mathrm{C}$ under $\mathrm{N}_{2}$ atmosphere. The corresponding TGA thermogram is shown in Figure 2.

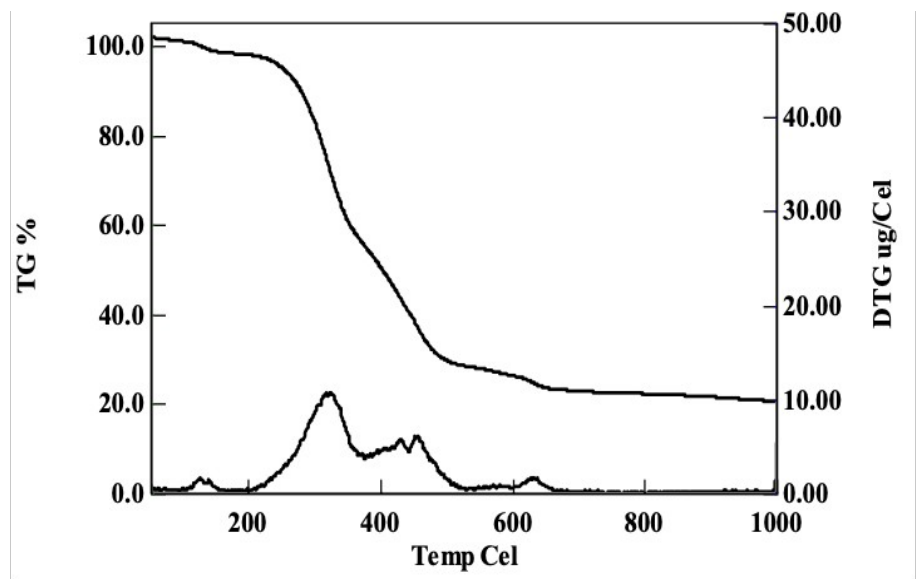

Figure 2. Thermogram of PEGGE-crosslinked $p(Q R)$ particles. 
The first degradation was obtained in the 118-154 ${ }^{\circ} \mathrm{C}$ range with slight weight loss about $1.4 \%$ because of bound water in the polymeric structure. Then, two main degradations were observed in 205-350 and $370-490{ }^{\circ} \mathrm{C}$ ranges with 39.2 and $69.6 \%$ cumulative weight loss, respectively. After $500{ }^{\circ} \mathrm{C}$, degradation was slightly increased with $79.4 \%$ cumulative weight loss. As reported in an earlier study, QR monomer was reported to be thermally more stable than PEGGE-crosslinked $p(Q R)$ particles up to nearly $900{ }^{\circ} \mathrm{C}$ because of more oxyethylene structure coming from the PEGGE crosslinker into the particle network (3).
Zeta potential values of $\mathrm{p}(\mathrm{QR})$ particles were measured in $\mathrm{pH} 2-12$ solution to determine the isoelectric point, as shown in Figure 3a. According to the results, $\mathrm{p}(\mathrm{QR})$ particles had slightly positive character with $+5.5 \pm 3.2 \mathrm{mV}$ at $\mathrm{pH} 2$ in acidic pHs, whereas zeta potential values gradually decreased to -27.2 from $-3.7 \mathrm{mV}$ up to $\mathrm{pH} 7$ and were almost stable at $\mathrm{pH}$ 7-12 with more negative charges. The isoelectric point of $\mathrm{p}(\mathrm{QR})$ particles was found to be $\mathrm{pH} 2.5$ where the zero zeta potential value was measured and there is a balance between positive and negative charges on the particle surface.
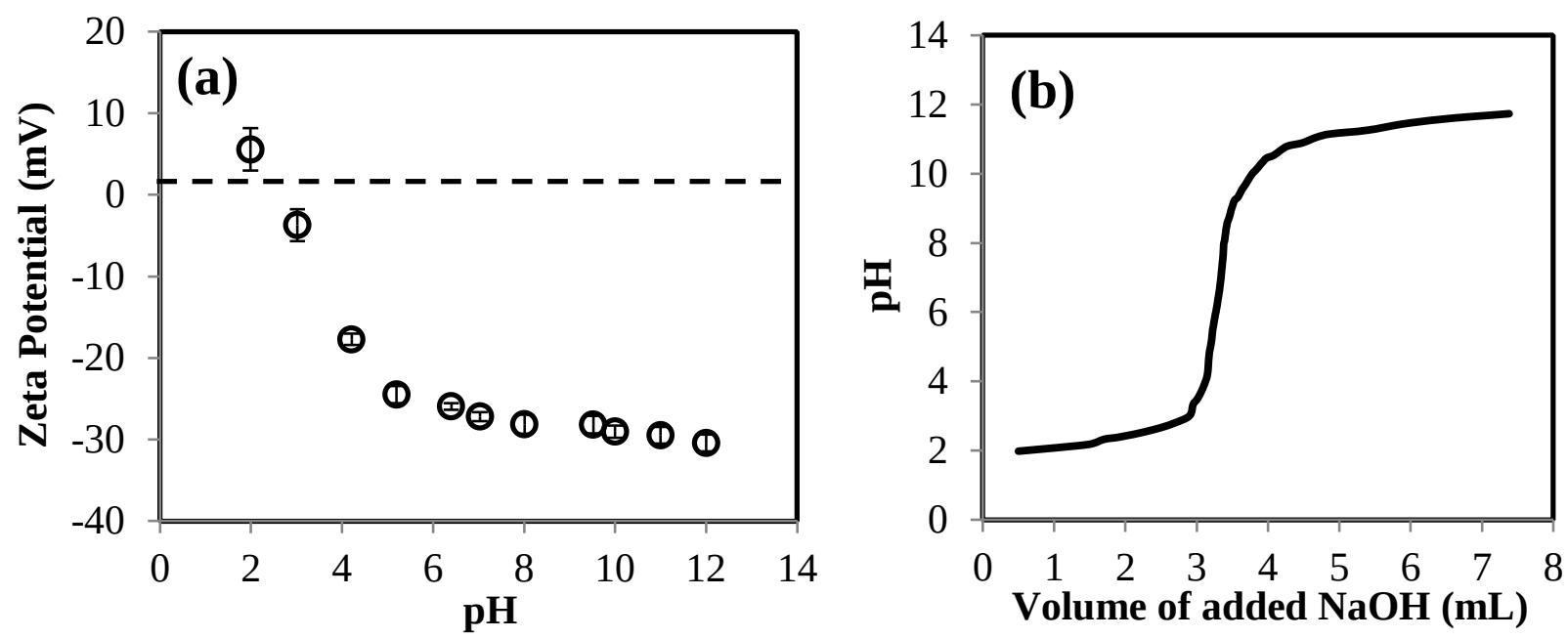

Figure 3. (a) Zeta potential values of $p(Q R)$ particles in different solution $\mathrm{pHs}$, and (b) potentiometric titration of $\mathrm{p}(\mathrm{QR})$ particles by using $0.1 \mathrm{M} \mathrm{NaOH}$ aqueous solution.

Furthermore, potentiometric titration of $p(Q R)$ particles was carried out in $\mathrm{pH} 2-12$ range to calculate equivalent point and $\mathrm{pKa}$ values of the $\mathrm{p}(\mathrm{QR})$ particles, as demonstrated in Figure 3(b). It was found that the equivalent point of $p(Q R)$ particles was about $\mathrm{pH} 7.6$ with $2.3 \mathrm{pKa}$ value. It is clear that $p(Q R)$ particles have only one $p K a$ value coming from the phenolic hydroxyl groups in the particle structure and the $\mathrm{pKa}$ value of $\mathrm{p}(\mathrm{QR})$ particles was very close to the isoelectric point of the particles as expected since some of the hydroxyl available on QR molecules are used up during crosslinking with PEGGE. These results support the view that $\mathrm{p}(\mathrm{QR})$ particles are negatively charged at physiological conditions, e.g., at $\mathrm{pH} 7.4$, and these negative $\mathrm{p}(\mathrm{QR})$ particles can readily interact with positively-charged biomacromolecules including some enzymes and proteins.

\section{Ferric reducing antioxidant power (FRAP Test) of $\mathbf{p}(\mathrm{QR})$ particles}

The FRAP test is an antioxidant test that is generally carried out at $\mathrm{pH}$ 3.6. It was reported that reduction of $\mathrm{Fe}(\mathrm{III})$ to $\mathrm{Fe}$ (II) ion by phenolic compounds can be used for the determination of their antioxidant power (25). Since, QR is not soluble in acetate buffer, the ethanolic solution of QR was used as comparison for $\mathrm{p}(\mathrm{QR})$ particles. As presented in Figure 4, the QR molecule reduces Fe(III) ions well compared with gallic acid (GA) which is generally used as reference. Gallic acid of $5 \mu \mathrm{g}$ and QR were found to reduce $\mathrm{Fe}(\mathrm{III})$ to $15.75 \pm 1.5 \mu \mathrm{g}$ and $9.4 \pm 1.74 \mu \mathrm{g} \mathrm{Fe}(\mathrm{II})$, respectively. The same amount of $p(Q R)$ particles $(5 \mu \mathrm{g})$ in acetate buffer resulted in $0.43 \pm 0.07 \mu \mathrm{g} \mathrm{Fe}(\mathrm{II})$. 


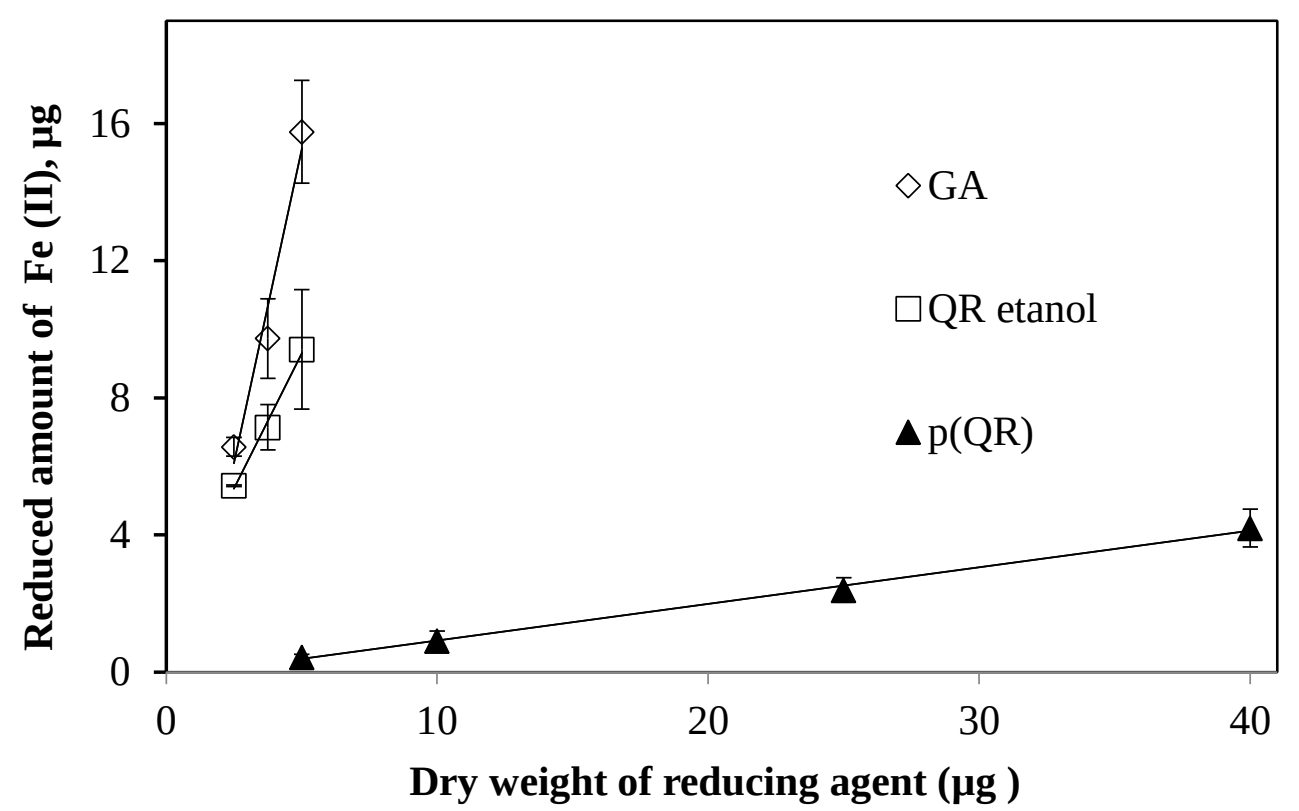

Figure 4. FRAP test for $Q R$ in ethanolic solution and $p(Q R)$ solution in acetate buffer at $p H 3.6$ (Gallic acid is used for comparison).

Although the $\mathrm{Fe}(\mathrm{III})$ reduction capacity of $\mathrm{p}(\mathrm{QR})$ seems to be lower than the QR molecule, $\mathrm{P}(\mathrm{QR})$ particles still have reducing capability as $10 \mu \mathrm{g}$ $\mathrm{p}(\mathrm{QR})$ can result in about $1 \mu \mathrm{g}$ of $\mathrm{Fe}(\mathrm{II})$ ions. The reducing capacity of $\mathrm{p}(\mathrm{QR})$ particles revealed a linear relationship with amount of $p(Q R)$ particles used and reduced forms of Fe(III) ions (Fe(II)).

\section{Total flavonoid content (TFC TEST) of $p(Q R)$ particles}

Total flavonoid content is another assay to determine the antioxidant properties of materials. The TFC of $\mathrm{QR}$ and $\mathrm{p}(\mathrm{QR})$ particles were examined, and the results are given in Table 1 . GA equivalent value $(\mu \mathrm{g} / \mathrm{mL})$ was taken as standard. It is apparent that $Q R$ molecules and $p(Q R)$ values are higher than GA. As GA is not a flavonoid, this outcome is reasonable. As $170 \mathrm{ppm}$ QR cannot be prepared in DI water, $170 \mathrm{ppm}$ QR solution was prepared in ethanol and used in TFC tests. The results for TFC and FRAP that were only tested for $5 \mu \mathrm{g}$ of material are summarized in Table 1.

Table 1. TFC (170 ppm) and FRAP $(5 \mu \mathrm{g})$ values for $\mathrm{GA}, \mathrm{QR}$ and $\mathrm{p}(\mathrm{QR})$ particles.

\begin{tabular}{|l|c|c|}
\hline Materials & *TFC (ppm) & *FRAP (5 $\mathbf{~ g})$ \\
\hline GA & 170 & $15.8 \pm 1.8$ \\
\hline QR & $275.3 \pm 22.6$ & $9.4 \pm 0.8$ \\
\hline p(QR) & $439.9 \pm 93.3$ & $0.4 \pm 0.1$ \\
\hline
\end{tabular}

* The results shown are expressed as means \pm SD of three independent experiments.

It is obvious from the table that the TFC values are much higher for $Q R$ and $p(Q R)$ in comparison to $G A$, and the FRAP values at low concentration of $5 \mu \mathrm{g}$ is much higher for $G A$ than for $Q R$ and $p(Q R)$. This is reasonable as GA has much higher Fe(III) reducing capacity than $\mathrm{QR}$ molecule and $\mathrm{p}(\mathrm{QR})$ particles. The antioxidant capacity of a phenolic compound strongly depends on the chemical nature of the flavonoid and the nature of the employed tests.

\section{The inhibitory effect of $p(Q R)$ particle on $\alpha$ - glucosidase}

The effect of $Q R$ and $p(Q R)$ particles on the enzyme activity of $\alpha$-glucosidase was determined by interacting them at $\mathrm{pH} 6.9$ in PBS. The inhibition values of $\alpha$-glucosidase enzyme are given in Figure 5 (a) and (b), respectively.

As clearly seen in Figure 5 (a), as the clf 112 concentration increased from 0.025 to $0.12 \mathrm{mg} / \mathrm{mL}$, the $\alpha$-glucosidase enzyme inhibition increased from 27.4 to $89.3 \%$ with an almost linear relationship between the amount of QR and the inhibition\% of $\alpha$ glucosidase enzyme. The $\mathrm{p}(\mathrm{QR})$ particles, on the other hand, as demonstrated in Figure 5 (b) revealed lower enzyme inhibition capability. From the figure, $\mathrm{p}(\mathrm{QR})$ particles can only inhibit $24.7 \%$ of $\alpha$ glucosidase enzyme at 0.06 unit $/ \mathrm{mL} \mathrm{mg} / \mathrm{mL}$ concentration against a maximum concentration of $1.0 \mathrm{mg} / \mathrm{mL}$. 

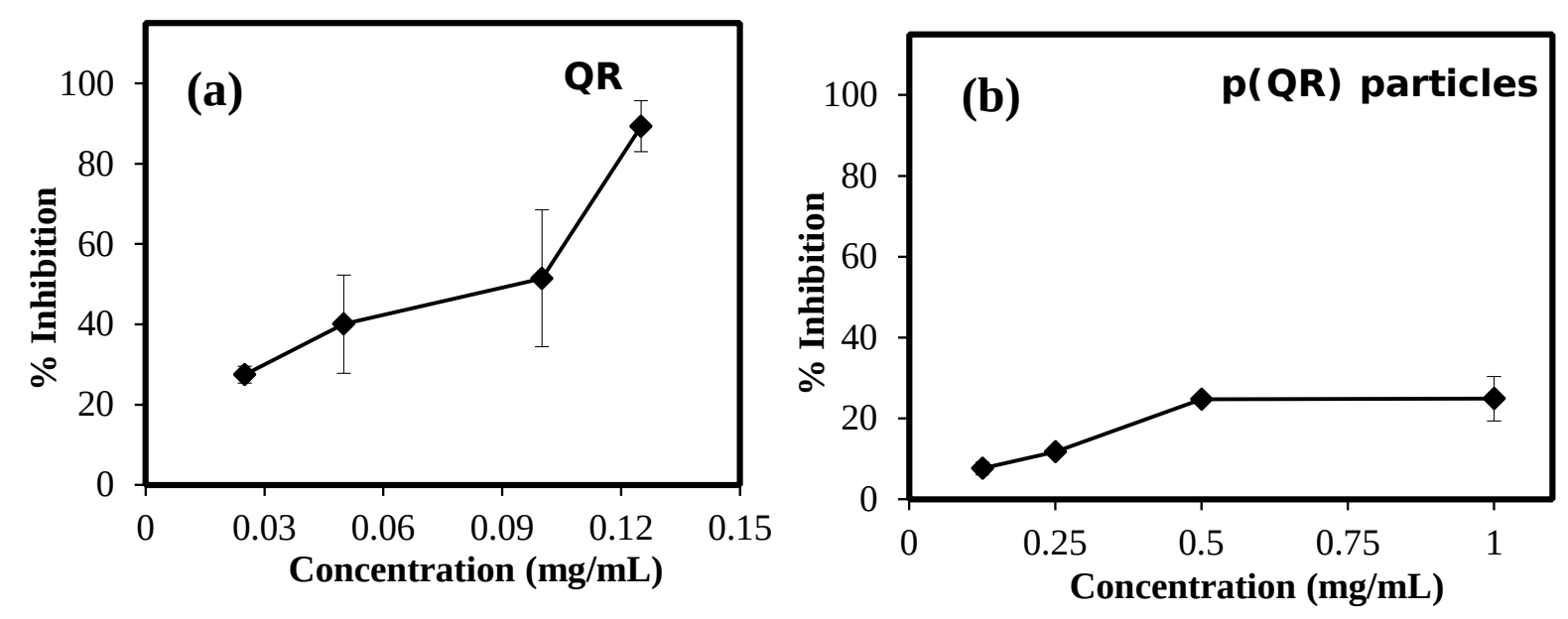

Figure $5 \alpha$-glucosidase enzyme inhibition \% of (a) QR molecules, and (b) p(QR) particles.

The interaction of $Q R$ and $p(Q R)$ particles with fibrinogen

In the coagulation process, fibrinogen, a plasma protein, interacts with thrombin to form fibrin. The protein structure and conformation are significant factors in retaining the activity of fibrinogen. Biomaterials can interact with plasma protein and may influence or trigger the clotting mechanism. Therefore, analysis of and changes in protein molecules upon interaction with biomaterials in the blood has paramount significance. Generally, fluorescence spectroscopy is employed as an effective and comparable tool to determine these interactions. Fluorescence intensity is related and associated with the number of tryptophan residues in fibrinogen and tryptophan residues are generally located in the hydrophobic core of fibrinogen (12). The change in the tryptophan residue conformation results in a change in the intensity of the fluorescent emission. So, fluorescence spectroscopy can be readily employed to probe the microenvironment of fibrinogen $(12,26)$.

$Q R$ and $p(Q R)$ were interacted with fibrinogen at varying concentrations and the corresponding fluorescence emission spectroscopy is presented in Figure 6 (a) and (b), respectively. The emission of fibrinogen at $0.1 \mathrm{mg} / \mathrm{mL}$ in DI water has a florescent intensity of about 64,700 at $341 \mathrm{~nm}$. As seen in Figure 6 (a), the peaks for fibrinogen started to decrease with the increase in the concentration $Q R$, e.g., $15,31,62.5,125$, and $250 \mu \mathrm{g} / \mathrm{mL}$. A similar test was also done for $p(Q R)$ particles as shown in Figure 6 (b). It is apparent from the figure that $p(Q R)$ particles are not as effective as QR molecules in reducing the fluorescence emission of fibrinogen. Only $250 \mu \mathrm{g} / \mathrm{mL} \mathrm{p}(\mathrm{QR})$ particles decreased the fibrinogen peak to 51762 intensity as seen in Figure 6 (b). 

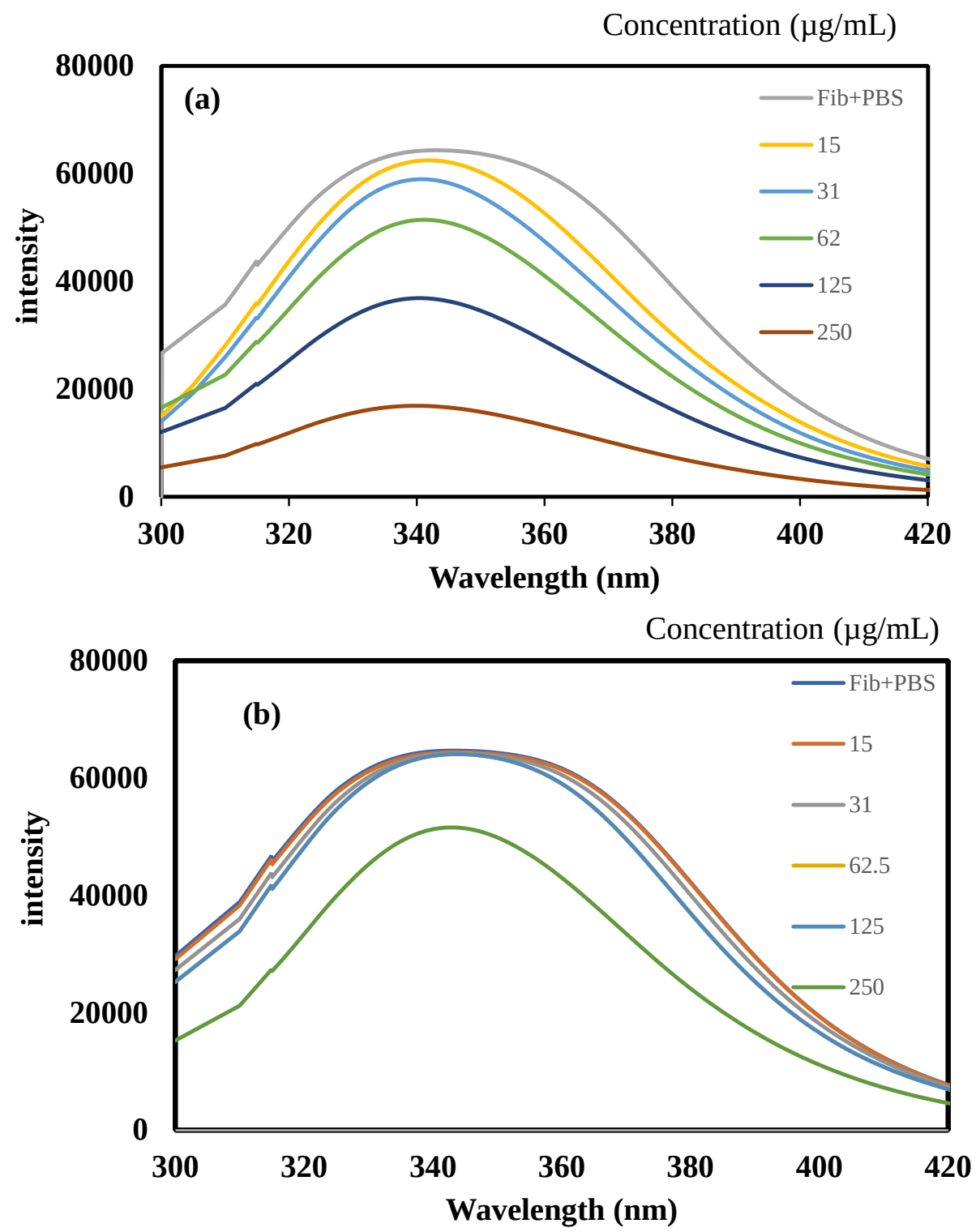

Figure 6. Fluorescent emission of (a) QR molecule (b) $p(Q R)$ particles at different concentrations [Excitation wavelength: $280 \mathrm{~nm}$ ].

Earlier, $\mathrm{p}(\mathrm{QR})$ particles were reported to degrade to about $2.4 \%$ in PBS over 100 hours at pH 7.4 (14), suggesting that lower amounts of QR molecules (e.g., $<15 \mu \mathrm{g} / \mathrm{mL}$ ) cannot trigger a clotting effect by interacting with fibrinogen residues in blood proteins. Therefore, $\mathrm{p}(\mathrm{QR})$ particles with controllable degradation profile can be used without triggering blood clotting.

\section{CONCLUSION}

The isoelectric point of $p(Q R)$ particles was found to be $\mathrm{pH} 2.5$ and the particles are negatively charged above this value. As $\alpha$-glucosidase inhibition is important in connection with diabetes, defined as abnormal elevation of blood glucose levels, and is associated with cardiovascular diseases such as hypertension, the use $\mathrm{p}(\mathrm{QR})$ to inhibit this enzyme may be very useful in biomedical applications. The hydrolytic enzymes such as $\alpha$-glucosidase play significant roles in controlling blood sugar for carbohydrate nutrition in the treatment of type 2 diabetes. The $\alpha$-glucosidase enzyme interaction with $\mathrm{QR}$ and $\mathrm{p}(\mathrm{QR})$ particles resulted in inhibition of the enzyme, suggesting higher inhibition values for QR molecules even at extremely low concentrations. As the degradation of $\mathrm{p}(\mathrm{QR})$ particles can be controlled with the amount of crosslinker (PEGGE) used, the amount of $\mathrm{QR}$ molecules released can also be controlled resulting in inhibition\% of the enzyme. These results show that QR is a good $\alpha$-glucosidase enzyme inhibitor and can be used for lowering blood sugar after digestion in patients with high blood sugar. The $\mathrm{p}(\mathrm{QR})$ particle, on the other hand, does not exceed $24.7 \%$ inhibition even at a concentration of $1 \mathrm{mg} / \mathrm{mL}$. It was also shown that fibrinogen residues in blood proteins can interact with QR molecule in concentration depending on manner as 
QR and $\mathrm{p}(\mathrm{QR})$ could affect the structure and conformation of fibrinogen. Also, $p(Q R)$ particles have negligible effect on fibrinogen residue suggesting that these particles can be readily used in blood contacting biomedical applications by specifically controlling the amount of QR molecules coming from the corresponding particles. Therefore, $\mathrm{QR}$ molecules and $\mathrm{p}(\mathrm{QR})$ particles may be used for biomedical applications. For example, QR molecules may be suitable for bleeding wounds or to control + bleeding after tooth extraction, while $p(Q R)$ particles maybe used up to $125 \mu \mathrm{g} / \mathrm{mL}$ concentration for intravenous applications without any thrombus.

\section{ACKNOWLEDGEMENT}

This work is supported by the Scientific Research Commission of Canakkale Onsekiz Mart University (COMU BAP, FBA-2018-2725).

\section{REFERENCES}

1. Buchweitz M, Kroon PA, Rich GT, Wilde PJ. Quercetin solubilisation in bile salts: A comparison with sodium dodecyl sulphate. Food Chem 2016 Nov;211:356-64.

2. Leopoldini M, Russo N, Toscano M. The molecular basis of working mechanism of natural polyphenolic antioxidants. Food Chem 2011 Mar;125(2):288-306.

3. Sahiner N. One step poly(quercetin) particle preparation as biocolloid and its characterization. Colloids Surfaces A Physicochem Eng Asp 2014 Jun;452:173-80.

4. Tan L, Zhou X, Wu K, Yang D, Jiao Y, Zhou C. Tannic acid/Call anchored on the surface of chitin nanofiber sponge by layer-by-layer deposition: Integrating effective antibacterial and hemostatic performance. Int J Biol Macromol 2020 Sep;159:30415.

5. Terao J. Factors modulating bioavailability of quercetin-related flavonoids and the consequences of their vascular function. Biochem Pharmacol 2017 Sep;139:15-23.

6. Cherubim DJ, Martins CV, Fariña L, Lucca RA. Polyphenols as natural antioxidants in cosmetics applications. J Cosmet Dermatol 2020 Jan 7;19(1):33-7.

7. Wang W, Sun C, Mao L, Ma P, Liu F, Yang J, et al. The biological activities, chemical stability, metabolism and delivery systems of quercetin: A review. Trends Food Sci Technol 2016 Oct;56:21-38.

8. Baldissarelli J, Santi A, Schmatz R, Zanini D, Cardoso AM, Abadalla FH, et al. Quercetin changes purinergic enzyme activities and oxidative profile in platelets of rats with hypothyroidism. Biomed Pharmacother 2016 Dec;84:1849-57.
9. Balasubramaniam V, Mustar S, Mustafa Khalid N, Abd Rashed A, Mohd Noh MF, Wilcox MD, et al. Inhibitory activities of three Malaysian edible seaweeds on lipase and $\alpha$-amylase. J Appl Phycol 2013 Oct 25;25(5):1405-12.

10. Zaharudin N, Salmeán AA, Dragsted LO. Inhibitory effects of edible seaweeds, polyphenolics and alginates on the activities of porcine pancreatic $\alpha$-amylase. Food Chem 2018 Apr;245:1196-203.

11. Zhu Y, Liu R, Wu D, Yu Q, Shea KJ, Zhu Q. Engineered polymer nanoparticles incorporating Lamino acid groups as affinity reagents for fibrinogen. J Pharm Anal 2020 Oct: doi:10.1016/j.jpha.2020.10.004

12. Deng L, Qi Y, Liu Z, Xi Y, Xue W. Effect of tannic acid on blood components and functions. Colloid Surface B 2019;184(September):110505.

13. Sahiner N, Sagbas S, Sahiner M, Silan C, Aktas N, Turk M. Biocompatible and biodegradable poly(Tannic Acid) hydrogel with antimicrobial and antioxidant properties. Int J Biol Macromol 2016; 82. 150-9.

14. Sahiner N, Sagbas S, Sahiner M, Aktas N. Degradable natural phenolic based particles with micro-and nano-size range. Recent Patents Mater Sci 2018;11(1). 33-40.

15. Tadapaneni RK, Banaszewski K, Patazca E, Edirisinghe I, Cappozzo J, Jackson L, et al. Effect of high-pressure processing and milk on the anthocyanin composition and antioxidant capacity of strawberry-based beverages. J Agric Food Chem 2012;60(23):5795-802.

16. Firuzi O, Lacanna A, Petrucci R, Marrosu G, Saso L. Evaluation of the antioxidant activity of flavonoids by "ferric reducing antioxidant power" assay and cyclic voltammetry. Biochim Biophys Acta - Gen Subj 2005 Jan;1721(1-3):174-84.

17. Li Y, Ma D, Sun D, Wang C, Zhang J, Xie Y, et al. Total phenolic, flavonoid content, and antioxidant activity of flour, noodles, and steamed bread made from different colored wheat grains by three milling methods. Crop J 2015;3(4):328-34.

18. Sahiner M, Blake DA, Fullerton ML, Suner SS, Sunol AK, Sahiner N. Enhancement of biocompatibility and carbohydrate absorption control potential of rosmarinic acid through crosslinking into microparticles. Int J Biol Macromol 2019;137.

19. Sahiner N, Sagbas S, Sahiner M, Blake DA, Reed WF. Polydopamine particles as nontoxic, blood compatible, antioxidant and drug delivery materials. Colloid Surface B 2018 Dec;172:618-26.

20. Sahiner M, Sahiner N, Sagbas S, Fullerton ML, 
Blake DA. Fabrication of Biodegradable

Poly(naringin) Particles with Antioxidant Activity and Low Toxicity. ACS Omega 2018;3(12).

21. Júnior SD da C, Santos JV de O, Campos LA de A, Pereira MA, Magalhães NSS, Cavalcanti IMF.

Antibacterial and antibiofilm activities of quercetin against clinical isolates of Staphyloccocus aureus and Staphylococcus saprophyticus with resistance profile. Int J Environ Agric Biotechnol 2018;3(5):1948-58.

22. Chen C, Zhou J, Ji C. Quercetin: A potential drug to reverse multidrug resistance. Life Sci 2010 Sep;87(11-12):333-8.

23. Wojdyło A, Samoticha J, Chmielewska J. Effect of different pre-treatment maceration techniques on the content of phenolic compounds and color of Dornfelder wines elaborated in cold climate. Food Chem. 2021 Mar;339:127888. doi:10.1016/j.foodchem.2020.127888

24. Dhanaraj T, Mohan M, Arunakaran J. Quercetin attenuates metastatic ability of human metastatic ovarian cancer cells via modulating multiple signaling molecules involved in cell survival, proliferation, migration and adhesion. Arch Biochem Biophys 2021 Feb;108795.

25. Zhao F-Q, Wang G-F, Xu D, Zhang H-Y, Cui Y-L, Wang Q-S. Glycyrrhizin mediated liver-targeted alginate nanogels delivers quercetin to relieve acute liver failure. Int J Biol Macromol 2021 Jan;168:93104.

26. Hu Q, Zhang $Y$, Wang $C, X u$ J, Wu J, Liu Z, et al. Hemocompatibility evaluation in vitro of methoxy polyethyleneglycol-polycaprolactone copolymer solutions. J Biomed Mater Res Part A 2016 Mar;104(3):802-12. 